Психология. Журнал Высшей школы экономики.

2017. T. 14. № 4. C. 644-656. DOI: 10.17323/1813-8918-2017-4-644-656

\title{
Cmamıu
}

\section{ВЫРАЖЕНИЕ ИНДИВИДУАЛЬНЫХ ПЕРЕЖИВАНИЙ И СТРУКТУРА ПСИХИКИ}

\author{
С.Б. КУЛИкОВ \\ ${ }^{2}$ Томский государствениый педагогиеский упиверситет, 634061, Россия, Томск, ул. Киевская, д. 60
}

\begin{abstract}
Резюме
В статье представлена тема реконструкции полемики между аналитическими философами и психологами с целью прояснения отношений мышления, языка и речи в процессе выражения индивидуальных переживаний. Применяя метод сравнительного анализа, автор представил аргументацию Л. Витгенштейна и его последователей в пользу вариантов редукции мыслительных операций к языку, а языка к логическим высказываниям. Выражение индивидуальных переживаний оказалось оправданным в результате их перевода в формы атрибутивных конструкций вида $a R b$. Данная процедура затруднила совпадение формы и содержания индивидуальных переживаний при их языковом выражении. Альтернативная точка зрения, представленная Ж. Пиаже, Л. Выготским и их современными комментаторами, подразумевает расширительное толкование психики, учет возрастных особенностей ее формирования. Были определены виды речи, а именно внешняя и внутренняя речь. Внешняя речь продемонстрировала прямую связь с мышлением и логическими формами языковых способов выражения индивидуальных переживаний. Внутренняя речь раскрыла возможности выражать индивидуальные переживания при связи мышления с языком, опосредованной воображением. В социокультурном отношении внутренняя речь оказалась каналом для трансляции индивидуальных переживаний при условии наложения импульсов, которые были созданы индивидом, на перформативные виды высказывания (раскрыты в теории речевых актов Дж. Остином). Новизна исследования заключается в представлении современных форм диалектики единого и многого, соотнесенной с полемикой относительно природы человеческой психики и каналов трансляции индивидуальных переживаний. В психологическом отношении результат раскрывает перспективы анализа структур психики, участвующих в опосредовании связей между мышлением и языком при выражении индивидуальных переживаний.
\end{abstract}

Ключевые слова: психология, аналитическая философия, природа психических процессов, умственная деятельность, выражение индивидуальных переживаний в психологии, язык и речь, внутренняя речь, античное наследие, диалектика единого и многого.

Исследование выполнено при поддержке Российского научного фонда (проект № 15-18-10002). 


\section{Введение}

В статье представлены результаты теоретического исследования возможностей выражения в языке и речи индивидуальных переживаний, аккумулирующих приватный опыт в повседневности, религии, искусстве и других сферах. Актуализируется полемика между философско-аналитической позицией Л. Витгенштейна и психологической точкой зрения Ж. Пиаже и Л.С. Выготского. Согласно первой позиции язык выражает индивидуальные переживания только опосредованно, путем прояснения набора признаков, при помощи которых можно характеризовать индивидуальные переживания в общем ключе их реализации. В отношении психики данная позиция предполагает редукцию актов мысли к актам описания. На этом пути открываются перспективы построения позитивной психологии, достаточно дискуссионные с современной точки зрения (Ciarrochi et al., 2013). В число следствий второй точки зрения входит положение, согласно которому индивидуальные переживания могут быть включены в состав различных видов психической деятельности, получить специфическое место и обнаружить адекватные способы выражения. Такая точка зрения подразумевает представление человеческой психики в виде комплексного образования, в котором язык и мышление играют одну из ведуших ролей, но не являются единственными средствами выражения индивидуальных переживаний.

Л. Витгенштейн не встречался при жизни с Ж. Пиаже и Л.С. Выготским, и нет объективных дан- ных - ссылок в публикациях, дневниковых записей - о том, что Л. Витгенштейн был знаком с их работами. Некоторые особенности личного характера заставляют предположить, что Л. Витгенштейн и не стал бы читать работы Ж. Пиаже и Л.С. Выготского. Современные исследователи предполагают, что психологи знакомились с работами Л. Витгенштейна и как-то реагировали на них (Smith, 2009). В свете данного предположения оказывается не удивительно, что многие идеи Л. Витгенштейна разных этапов его творческой биографии демонстрируют скрытые полемические выпады против тезисов Ж. Пиаже и Л.С. Выготского, а некоторые поздние работы, например «Философские исследования», содержат идеи, прямо полемизирующие с идеями психологов.

В то же время следует учитывать, что в статье предлагается реконструкция полемики, а не ее механическое воспроизведение. Автор полагает возможным в итоге продемонстрировать, что полученные результаты имплицитно присущи ходу полемики, хотя явным образом они формулировались далеко не во всех случаях. Дается интерпретация столкновения философских и психологических воззрений относительно связи индивидуальных переживаний и структуры психики. Такой подход принципиально важен, поскольку именно он раскрывает диалектику единого и многого в отношении понимания мира человеческих переживаний, указывая тем самым на непреходящее значение античных способов осмысления действительности.

В исследовании, реализующем методы сравнительного анализа и 
феноменологической реконструкции, разбираются феномены внутренней и внешней речи в их отношении к возможностям выражения индивидуальных переживаний. Основное содержание статьи включает два раздела. В первом разделе представлена проблемная ситуация, сложившаяся в отношении возможностей языка и речи выражать индивидуальные переживания. Показаны следствия редукции мышления к языку, а языка к логике. Во втором разделе дана критика позиции Л. Витгенштейна, согласно которой всякое суждение может быть только атрибутивным и выглядеть как $a R b$ («а» соответствует характеристике, признаку «b»), а прочие суждения должны игнорироваться как бессодержательные псевдосуждения, не несущие позитивной информации. Именно этот раздел, несмотря на то, что в нем практически не встречаются имена Ж. Пиаже и Л.С. Выготского, в полной мере показывает значение их психологических идей в отношении критического переосмысления философских идей Л. Витгенштейна о возможности адекватного выражения индивидуальных переживаний в языке.

Необходимо также отметить, что в силу значимости работ Ж. Пиаже и Л.С. Выготского в англоязычных дискуссиях ссылки даются на английские переводы их сочинений. Кроме того, именно обсуждение идей, представленных в зарубежных дискуссиях, послужило причиной, по которой автор опирался на англоязычные разработки, а не на отечественные исследования.

\section{Индивидуальные переживания и редукционизм в понимании психических процессов}

Вопрос о выражении индивидуальных переживаний в языке тесно связан с вопросом о пределах, в которых высказывания могут быть построены в типах речи, а именно во внешней речи, используюшейся для межличностного общения, и внутренней речи, применяемой для общения личности с собой. Вопрос этот не тривиален, ибо именно наличие самой возможности внутренней речи, открытой Ж. Пиаже (Piaget, 1998), осмысленной Л. Выготским (Vygotsky, 1986) и описанной в работах P. Андерсон (Anderson, 1982), A. Бэддли и В. Льюиса (Baddeley, Lewis, 1981), а также в трудах В. Колхарт (Coltheart, 1999) и М. де Герреро (De Guerrero, 1999), раскрывает трудности в безоговорочном принятии тезиса Л. Витгенштейна, который указывает на проблематический характер выражения индивидуальных переживаний и согласно которому «О чем говорить нельзя, о том следует молчать» ("whereof one cannot speak, thereof one must be silent" TLP, 7$)^{1}$. По причинам, которые станут

${ }^{1}$ Ссылки на работы Л. Витгенштейна даются по стандартам, принятым в международных публикациях. «Логико-философский трактат» («Tractatus Logico-Philosophicus») об́означается как TLP с упоминанием номера конкретной секции. Ссылки на работу «Философские исследования» («Philosophical Investigations», PI) оформляются в виде указания конкретных параграфов в составе сочинения. 
понятны позднее, индивидуальные переживания - это как раз то, о чем «говорить нельзя».

Вместе с тем Л. Витгенштейн в противоположность описанным им вариантам представления логических пропозиций не уточнял конкретного вида высказываний, которые не могут быть произведены в случаях невыразимости признаков определенного класса явлений. Остается предполагать, попадают ли в состав этого класса явления по типу «сущность», «высшие причины» и др. Но понять, что конкретно имел в виду Л. Витгенштейн, говоря о том, что «говорить нельзя», довольно трудно. Не вполне понятно, в каком плане выстраивается само это «говорить» (нем. sprachen, анел. speak). «Говорить» можно в смысле придания знакам (символам) значения, т.е. связывая с конкретными предметными областями, а можно в ситуации частного вида передачи информации, не обязательно отсылающего к конкретной предметной области. В данном отношении внутренняя речь, которая может и не выражаться в форме упорядоченного набора символов, вполне допускает случаи, когда есть шансы «говорить» и о том, о чем при помощи символов «говорить нельзя». Потенциалом к данному общению обладает коммуникация на уровне физических контактов между коммуникантами, не вступившими в прямой диалог друг с другом, но убедившими самих себя в дружеском или враждебном отношении к собственной персоне. Кроме того, и среди прочих видов внешней речи также есть способы коммуникации, позволяющие обойти запрет Л. Витгенштейна. Чтение написанного текста является случаем, когда читающий «говорит», причем в этом плане оказывается допустимым «говорить» и о том, о чем «следует молчать».

Нужно, однако, отметить, что приведенных аргументов недостаточно. В современных условиях многие специалисты, сторонники Л. Витгенштейна, продолжают скептически относиться и к когнитивным функциям внутренней речи, и к другим вариантам выхода из обозначенной проблемной ситуации (Fenk, 2013), поэтому исследовательскую работу необходимо продолжить.

Интерпретация суждения «О чем говорить нельзя, о том следует молчать» раскрывает важную теоретикопсихологическую проблему. Необходимы основания для описания процессов, в которых при спонтанном зарождении индивидуальных переживаний имелся бы адекватный способ их трансляции. Причем способ этот должен соответствовать индивидуальным параметрам возникновения исходного переживания (например, чувства голода) и не вести к его переводу в систему общезначимых вариантов передачи информации. Основания для последнего заявления имеются следующие. Всегда есть шанс указать группу родственных обозначений, передающих информацию о голоде по смежности или по сходности двух разных переживаний между собой, поэтому метонимическое или метафорическое выражение чувства голода не составляет проблемы. Можно сказать: «Лекарство принимают на голодный желудок». Но приемлемо говорить и «Я голоден», разумея под этим страсть к собиранию почтовых 
марок или стремление к сочинению стихов. Эти пути ведут к подмене исходных интенций, имеющихся у человека в момент складывания индивидуального переживания. Общие формы общения не содержат точных способов передачи чувства голода именно этого человека и именно в той форме, как он это иснытывает. Ни у кого, кроме конкретного человека, нет точно такой же пустоты в желудке, да и голод как метафору страсти примет не всякий. Именно здесь выявляется случай того, что исходно должна быть выполнена речь без наделения предмета высказывания отличными от него качествами и свойствами (по виду $a R b$ ). С формальной стороны точным выражением переживания «Я голоден» будет «Я голоден, значит, я голоден», т.е. $a R a$. Остальные способы выражения окажутся неточны, ибо «Я голоден, потому что хочу кушать» требует уточнения, что значит «хочу», «кушать» и т.д.

В то же время Л. Витгенштейн, налагая в «Логико-философском трактате» запрет на высказывания, не несущие положительной информации, но и не уточняя случаи, когда и по какому поводу все-таки в действительности «нельзя говорить», демонстрирует поразительную разговорчивость во всех остальных моментах. Причем не все эти моменты связаны только с атрибутивными высказываниями.Л.Витгенштейн рассуждает о фактах и вещах, о логике и естествознании, говорит о музыке и образах. Вместе с тем смысл трактата не вполне ясен. Возможно, что в моменты высказываний Л. Витгенштейн имел в виду нечто иное, нежели, например, действи- тельное выражение трансцендентальности логики (TLP, 6.13) и этики (TLP, 6.421), позволяющее провести между ними параллель. Именно для прояснения данных моментов необходимо обращение к идее внутренней речи и к ее характеристикам.

Из работ Ж. Пиаже и Л.С. Выготского (Piaget, 1998; Vygotsky, 1986) известно, что суть идеи внутренней речи состоит в раскрытии смысла процессов формирования речи у ребенка в детстве и его подготовки к усвоению научных понятий при обучении чтению. Речь ребенка уже и на начальном этапе процесса (в возрасте трех лет) вполне развита для общения, оставаясь не до конца совершенной для общения с окружающими людьми именно на понятном для всех языке. Дети находятся в аутическом состоянии и используют эгоцентрический язык, который позволяет выражать индивидуальные переживания при помощи личных слов (Piaget, 1998, р. 28). Именно этим языком ребенок и пользуется, обращаясь к окружающим. Причем можно спорить, проходят ли буквально все дети через стадию аутичной замкнутости, но совершенно точно, что даже на самых ранних ступенях развития дети применяют речь как социальный инструмент. Используемая в обществе внутренняя речь демонстрирует социальные корни, во всяком случае современные исследования в психолингвистике убедительно показывают, что такая речь есть интернализация внешней речи (Ehrich, 2006; Jones, 2009). Однако общение выполняется для достижения сингулярных целей, и только к возрасту около семи лет дети учатся строить высказывания в 
утилитарном плане и готовы к освоению простейших научных понятий (Vygotsky, 1986, p. 147-148).

В целом развитие языка и речи может быть описано как длительный процесс, обусловленный социальными контактами детей, проходящих ряд стадий в формировании внутренней речи. Развиваясь из эгоцентричной речи, внутренняя речь определяется самыми ранними опытами детей в освоении мира. Можно даже предположить, что внутренняя речь имеет функции, отличные от функций внешней речи, и совершенно естественно, что между ними прослеживаются синтаксические различия. Для внутренней речи обычной выступает предикация, построенная на избегании предметов и предпочтении вторичных признаков. Яблоко это «вкуснотища», а не просто «яблоко». Солнце - это нечто яркое и теплое, а не только «солнце». Смысл высказываний, значение используемых слов и контексты их применения отличают внутреннюю речь от внешней речи. Если в последней смысл и значения достаточно строго задаются предметными областями и потому взаимно обусловлены, то в процессе реализации внутренней речи смысл оказывается нестабилен, он флуктуирует, тогда как значение стремится к унификации. Совершенно разные люди: мать, воспитательница в детском саду, случайно встреченная женщина на улице - все они в сознании ребенка могут обозначаться одним словом. Причем для ребенка нет затруднений и в том, чтобы один и тот же объект именовался в одно и то же время разными словами, например, сам ребенок, его роль в играх и исполнитель этой роли. При этом важно понимать, что данные характеристики относятся именно к детскому мышлению, выражающемуся в детской речи, формируясь в период от трех до семи лет. Почему не вполне состоятельны попытки дезавуировать идеи об ориентированности внутренней речи на значение, а не смысл, которые осуществляют современные авторы на материале старших групп испытуемых (Jones, 2009)

Характеристики внутренней речи могут быть соотнесены с феноменом следования правилу, который Л. Витгенштейн в «Философских исследованиях» связал с возникновением особого парадокса. Смысл парадокса заключается в том, что нельзя нечто высказывать ни себе, ни другим, не следуя правилу, но следование правилу и есть способ высказывать это нечто, и потому никто не может следовать правилу, следуя ему (PI, 201). Например, кто-либо решил сказать: «Мне холодно! Закройте окно, пожалуйста». По правилам русского языка, необходимо различить прямую и косвенную речь в данном высказывании. Однако при выражении пожелания «Закройте окно» мало кому в голову придет до этого сказать себе: «А теперь - прямая речь: “Мне холодно! Закройте окно, пожалуйста”». И уж совершенно точно никто в стандартной ситуации не станет уточнять, на каких местах и почему должны стоять знаки препинания. Все случаи подобных расшифровок выполняются только во внешней речи. Так, в театральных постановках возможны дополнительные ремарки, поясняющие суть дела. Плюс пояснения используемых правил делаются на уроке русского 
языка или при обучении данному языку людей, не говорящих на нем от рождения. Даже если ученик повторяет про себя выученные правила, он тем самым включается в заочный диалог с преподавателем, и уже потому нельзя полностью утверждать, что используется внутренняя речь. В повседневных же условиях правила заданы практикой использования языка, которую говорящие усвоили в процессе овладения языком и речью и которую принимают как данность, в то время как все это всего лишь элементы спонтанно сложившейся языковой игры. Отсюда, среди прочего, следует, что язык есть социальное явление и быть индивидуальным не может.

Обратим вместе с тем внимание на суть идей, выдвинутых Ж. Пиаже и Л.С. Выготским относительно внутренней речи. Выражая свои переживания и для себя, и для окружающих, дети используют индивидуальный, приватный язык. Различий между внутренней и внешней речью они не демонстрируют. Поэтому критика Витгенштейна не учитывает психологического разрыва между компетенциями ребенка и умениями взрослого. Конечно, это не отменяет самого парадокса следования, ибо ребенок, произнося индивидуальные слова, употребляет их по правилам, свойственным именно его способу высказываться.

Становится возможным заключить, что философские идеи Л. Витгенштейна в «Логико-философском трактате» и в «Философских исследованиях» находятся в системе двойственных отношений к итогам психологических исследований, полученных Ж. Пиаже и разви- тых Л.С. Выготским. С одной стороны, феномен внутренней речи, ориентированной на строгую фиксацию значений и демонстрирующей слабую связь с требованиями обязательности наличия смысла высказываний, позволяет обойти запрет на бессодержательные высказывания, сформулированный в трактате. Этот запрет касается взрослых и не относится к детям. Более того, самого Л. Витгенштейна можно заподозрить в проявлениях детской непоследовательности суждений, ибо, запрещая другим нечто высказывать, сам он совершает такие высказывания. Возможно, именно так, т.е. как признание собственных слабостей, следует понимать тезис 6.54, суть которого в том, что при правильном понимании положений трактата все они бессмысленны. С другой стороны, внутренняя речь воспроизводит парадокс следования вне зависимости от того, насколько осмысленными являются сами по себе фразы, построенные ребенком или взрослым. Выявленные моменты требуют обращения особого внимания на варианты построения суждений, психологических механизмов, которые позволяют преодолеть запреты на бессодержательные высказывания при адекватном выражении индивидуальных переживаний.

\section{Выражение индивидуальных переживаний в языке при расширительном толковании состава психики}

Теоретико-психологическое понимание проблемы выражения индивидуальных переживаний подразумевает поиск оснований для 
выполнения данного выражения в виде, максимально точно соответствующем природе самого переживания. В этом отношении полем, на котором произрастает любое переживание, являются психика и ее структуры. В связи с этим неправомерным является сведе́ние возможностей выражения индивидуальных переживаний к какой-то одной стороне психики, пусть одной из ведущих, но не единственной. Однако, оценивая перспективы оформления суждений относительно индивидуальных переживаний, Л. Витгенштейн исходил из установки о взаимной обусловленности мышления и логики, с одной стороны (TLP, 3.03), а также логики и языка - с другой. Выражать нечто в языке противоположно логике невозможно, как и строить фигуры в геометрии противоположно законам пространства (TLP, 3.032). Таким образом, мышление и язык связаны между собой настолько, что о том, что не мыслится ясно, не может быть ничего сказано, и наоборот. Поэтому можно смело утверждать, что с психологической точки зрения Л. Витгенштейн выполняет редукцию структур психики к одному ее элементу, а именно к мышлению. Именно в этом видятся возможности выхода из противоречия, возникающего в границах утверждений Л. Витгенштейна. Внутренняя речь, индивидуальный язык позволяют выражать индивидуальные переживания, хотя они и неспособны как таковые отображать нечто осмысленным образом. Иначе говоря, внутренняя речь оказывается и речью и не речью одновременно, ибо она нелогична, т.е. немыслима. Вместе с тем стан- дартное в психологии различение структурных компонентов психики, выделение наряду с мышлением памяти, воображения и других структур позволяет развести варианты порождения, формулировки и выражения индивидуальных переживаний по разным сферам компетенции. Тогда есть все основания связать внешнюю речь с мышлением, а внутреннюю речь можно отнести не к мышлению, но к любой другой структуре психики, допустим, к воображению. В этом случае внутренняя речь не обязана подчиняться законам логики, в ней можно сочетать как связность и содержательность высказываний, так и их относительную бессвязность и бессодержательность.

Традиция, сложившаяся в русле исследований Л. Витгенштейна, позволяет оценить полученные ранее результаты следующим образом. По понятным соображениям, разработки не затрагивали в качестве ключевых вопросов отношения языка и мышления с другими сторонами психики. И у самого Л. Витгенштейна, и у его последователей работа велась в перспективе прояснения способов высказывания, демонстрируя расширение сферы применения исходных положений с логики и науки на сферу повседневности как среды, в которой функционирует язык. Тем ценнее соотнести достигнутые результаты с наработками Ж. Пиаже, Л.С. Выготского и других психологов. Показательно, что, двигаясь в разных направлениях, витгенштейнианцы и психологи пришли во многом к одинаковым итогам.

Один из непосредственных продолжателей исследований Л. Витген- 
штейна Дж. Остин еще в середине XX в. предложил теорию речевых актов. Частные приложения этой теории позволяют переосмыслить соотношение языка и мышления, во всяком случае того, что касается повседневного их применения. Теория речевых актов раскрыла феномен перформативных высказываний или просто «перформативов» (Austin, 1962, p. 13-14). Перформативные высказывания объединяют речь о каком-либо действии, предмете и само это действие в единое целое. Примером может служить любое распоряжение, приказ, отданные в целях получения реакции от того, к кому они адресованы. Так, преподаватель входит в аудиторию к студентам, видит открытое окно и настоятельно рекомендует: «Закрыть!». Студенты закрывают окно, и в этот момент создается особая ситуация, в которой слово и дело объединяются. Перформативные высказывания не просто описывают вещи или действия, они сами производят такие вещи и действия. Допустим, кто-то спрятал теннисный мячик за спину, а потом показал его окружающим и сказал одновременно с этой демонстрацией: «Мяч!» В этом случае слово и предмет, на которое указало слово, совпадут.

В теории речевых актов, развиваемой некоторыми современными исследователями, выполняется переосмысление традиционной теории значения, подразумевающей под значением замещение, референцию вещей и действий структурами языка. Дж. Остин отстаивал идею контекстуального определения значений, согласно которой язык не может быть определен набором референци- альных правил. В итоге язык предстал образованием, детерминированным комплексом явлений, таких как локутивный акт, перлокутивный эффект, иллокут ивные силы. В работе М. Киссина суммированы современные воззрения на определения данных явлений (Kissine, 2008). М. Киссин интерпретирует теорию речевых актов, прибегая к философии деятельности Д. Дэвидсона (Davidson, 1963). Локутивные акты охватывают варианты реакции коммуникантов на поступившее предложение, причем выполненные ради самого общения. М. Киссин приводит в пример декламацию. Но можно привести и другой пример. Так, на предложение не плакать, плачущий человек может сказать: «Хочу, и плачу! Плакал, плачу и буду плакать!» Перлокутивные эффекты служат для демонстрации смысла высказывания. Например, если некто скажет: «Не плачь!», то прекращение или продолжение плача свяжет действия тела и речевой акт в единое целое. Не менее простую иллюстрацию можно дать иллокутивным силам, подразумевающим возможности конвенционального принятия высказываний. Близкий человек, согласно своему статусу, может велеть кому-то прекратить плакать. Условием конвенции становится знакомство обоих участников общения как друг с другом, так и с ситуацией, вызвавшей плач. Человек, видящий плачущего впервые, не может сразу дать команду о прекращении плача, во всяком случае, не выяснив его причины. Вполне может оказаться, что плач носит ритуальный характер, и прекращение плача будет означать прегрешение против правил ритуала. 
Теория речевых актов послужила поводом для серьезной научной дискуссии. В ее адрес выдвигались и продолжают выдвигаться критические замечания. Так, П. Стросон высказал сомнение относительно конвенциональной природы иллокутивных сил, могущих демонстрироваться в виде генеральной схемы соб́ственного понимания (Strawson, 1964). Точка зрения П. Стросона нашла подкрепление в работах П. Грайса, указавшего на затруднительный характер различения естественных и искусственных значений (Grice, 1996). В этом случае затруднительно говорить о том, что высказывания, обеспечивающие собственное принятие, вводятся благодаря конвенциям. Большое число речевых актов может быть принято благодаря естественным условиям своего возникновения, поэтому есть онтологические и эпистемологические сомнения в состоятельности теории речевых актов. Эти сомнения высказывали в своих работах Дж. Сёрл (Searle, 2002), а также Дж. Пилотта и A. Микунас (Pilotta, Mickunas, 1990). Однако эти замечания носят сугубо философский характер, показывая сложность предложенных Дж. Остином идей, а не выступают свидетельством полной несостоятельности теории речевых актов.

В контексте обсуждаемых вопросов о выражении индивидуальных переживаний, возможностей их адекватной трансляции во внешней и/или внутренней речи теория речевых актов играет принципиально важную роль. Идеи Л. Витгенштейна, предполагающие необходимость связи речи, языка и мышления с логикой, имеют следствием необхо- димый вывод, что выражение индивидуальных переживаний в принципе не может быть адекватным. Такое выражение не способно отвечать характеристикам атрибутивных высказываний, не несет положительной информации и, соответственно, должно быть отнесено к тому, о чем «следует молчать». Вместе с тем идеи Дж. Остина, раскрывающие целесообразность привлечения перформативов для выражения индивидуальных переживаний, позволяют переосмыслить ситуацию. Внешняя речь, построенная в виде перформативного высказывания, способна совпадать с характеристиками внутренней речи, выделенными Ж. Пиаже и осмысленными Л.С. Выготским. Для этого необходимо допустить внерациональные варианты общения, например, при непосредственном обмене эмоциями. Трудно сказать, что на самом деле значит словосочетание «сияющие от счастья глаза», но всякий человек, наблюдавший подобное выражение чьих-то глаз, поймет состояние их владельца. Гипотетическое совпадение импульса, сгенерированного перформативным высказыванием, с набором высказываний, сформулированных во внутренней речи, открывает перспективы прямого выражения индивидуальных переживаний. В этой перспективе логическое мышление и его нормы играют вторичную роль, более существенную ценность приобретает воображение. Воображение способно помочь в ходе общения достроить, развить идеи, не высказанные собеседниками напрямую. Впрочем, вполне справедливо было бы и допущение, что в процессе передачи индивидуальных переживаний, 
помимо воображения, способны сыграть свою роль и другие структуры психики, например память. В дальнейшем доказательство этих положений потребует дополнительных исследований на пересечении философии и психологии.

\section{Заключение}

В ходе реконструкции полемики между аналитическими философами и психологами касательно отношений мышления, языка и речи в процессе выражения индивидуальных переживаний были получены следующие результаты. Представлена аргументация Л. Витгенштейна в поддержку редукции мыслительных операций к языку, а языка к логическим высказываниям. Выражение индивидуальных переживаний, индивидуального опыта оказалось оправданным в результате перевода в формы атрибутивных конструкций вида $a R b$. Данная процедура затруднила совпадение формы и содержания индивидуальных переживаний при их языковом выражении. Альтернативная точка зрения, представленная Ж. Пиаже и Л.С. Выготским, подразумевала расширительное толкование психики, учитывающее воз- растные особенности ее формирования. Были определены виды речи, а именно внешняя речь и внутренняя речь. Внешняя речь продемонстрировала прямую связь с мышлением и логическими формами языковых способов выражения индивидуальных переживаний. Внутренняя речь раскрыла возможности выражать индивидуальные переживания при связи мышления с языком, опосредованной воображением. Доказано, что в социальном и социокультурном отношении внутренняя речь становится каналом для трансляции индивидуальных переживаний при условии наложения импульсов, которые были созданы индивидом, на перформативные формы высказывания (раскрыты в теории речевых актов Дж. Остином). Наиболее общим результатом исследования выступило представление современных форм диалектики единого и многого, соотнесенной $\mathrm{c}$ полемикой о природе человеческой психики и каналах трансляции индивидуальных переживаний. В психологическом плане результат раскрывает перспективы анализа структур психики, участвующих в опосредовании связей между мышлением и языком при выражении индивидуальных переживаний.

Ссылки на зарубежные источники см. в разделе References после англоязыиного блока.

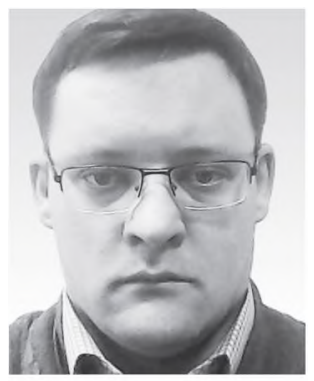

Куликов Сергей Борисович - декан, факультет общеуниверситетских дисциплин,Томский государственный педагогический университет, доктор философских наук, доцент.

Сфера научных интересов: когнитивная психология, история и философия науки, сопоставление возможностей феноменологии и аналитической философии в отношении когнитивных практик.

Контакты: kulikovsb@tspu.edu.ru 


\title{
Expression of Private Experiences and Structure of Psyche
}

\author{
S.B. Kulikov \\ ${ }^{a}$ Tomsk State Pedagogical University, 60 Kievskaya Str., Tomsk, 634061, Russian Federation
}

\begin{abstract}
The article presents a theme of reconstruction of the polemic between analytic philosophers and psychologists concerning the relations of thought, language and speech in expression of private experiences. The method of comparative analysis helped the author to elaborate $\mathrm{L}$. Wittgenstein's argument for reduction of cogitative operations to language, and language to logical propositions. Expression of individual experiences becomes aRb justified because of their transfer to forms of attributive kind. This procedure complicated the congruence of form and content of private experiences in speech. The alternative point of view presented by psychological ideas by J. Piaget and L. Vygotsky, as well as their contemporary expounders, provides the extended interpretation of mind considering its development across the lifespan. Types of speech, namely the external speech and the inner speech, were distinguished. The external speech showed the direct link with thought and logical forms of language to express private experiences. The inner speech disclosed opportunities to express private experiences via connection of thought with language mediated by imagination. In social-cultural regard, the inner speech becomes the channel for translation of private experiences by imposing impulses created by the person on performative forms of the statement (were disclosed in the Theory of Speech Acts by J. Austin). The novelty of the research is contained in the introduction of the modern forms of Unity-Variety dialectics, correlated to the polemic on the nature of human mind and channels for translation of private experiences. In psychology, the result opens prospects to analysis of mind structures, which mediate thought and language in expression of private experiences.
\end{abstract}

Keywords: psychology, analytic philosophy, nature of psychic processes, mental processes, expressions of private experience in psychology, language and speech, inner speech, ancient legacy, Unity-Variety dialectics.

\section{References}

Anderson, R. E. (1982). Speech imagery is not always faster than visual imagery. Memory and Cognition, 10(4), 371-380.

Austin, J. L. (1962). How to do things with words. Cambridge, MA: Harvard University Press.

Baddeley, A. D., \& Lewis, V. (1981). Inner active processing in reading: The inner voice, the inner ear, and the inner eye. In A. M. Lesgold \& C. A. Perfetti (Eds.), Interactive processes in reading (pp. 107-129). Hillsdale, NJ: Lawrence Erlbaum.

Ciarrochi, J., Kashdan, T. B., \& Harris, R. (2013). The foundations of flourishing. In T. B. Kashdan \& J. Ciarrochi (Eds.), Mindfulness, acceptance, and positive psychology: The seven foundations of wellBeing (pp. 1-29). Oakland, CA: Context Press. 
Coltheart, V. (1999). Phonological codes in reading comprehension, short-term memory, and memory for rapid visual sequences. In V. Coltheart (Ed.), Fleeting memories cognition of brief visual stimuli (pp. 181-225). Cambridge, MA: The MIT Press.

Davidson, D. (1963). Actions, reasons and causes. Joumal of Philosophy, 60, 685-700. doi:10.1093/0199246270.001.0001

De Guerrero, M. C. M. (1999). Inner speech as mental rehearsal: The case of advanced L2 learners. Issues in Applied Linguistics, 10(1), 27-55.

Ehrich, J. F. (2006). Vygotskian inner speech and the reading process. Australian Joumal of Educational and Developmental Psychology, 6(3), 12-25.

Fenk, A. (2013). The cognitive functions of inner speech. In D. Moyal-Sharrock, V. A. Munz, \& A. Coliva (Eds.), Mind, language and action. Papers of the $36^{\text {th }}$ International Wittgenstein Symposium, August 11-17, Kirchberg am Wechsel (pp. 128-130). Kirchberg am Wechsel: The Austrian Ludwig Wittgenstein Society.

Grice, H. P. (1996). Meaning. In A. P. Martinich (Ed.), The philosophy of language (3rd ed.) (pp. 8591). New York: Oxford University Press.

Jones, P. E. (2009). From "external speech" to "inner speech" in Vygotsky: A critical appraisal and fresh perspectives. Language and Communication, 29, 166-181. doi:10.1016/j.langcom.2008.12.003

Kissine, M. (2008). "Locutionary, Illocutionary, Perlocutionary". Language and Linguistics Compass, 2(6), 1189-1202. doi:10.1111/j.1749-818x.2008.00093.x

Piaget, J. (1998). The language and thought of the child (4th ed.). London: Routledge.

Pilotta, J. J., \& Mickunas, A. (1990). Science of communication: Its phenomenological foundation. Hillsdale, NJ: Lawrence Belbaum Associates.

Searle, J. R. (2002). Individual intentionality and social phenomena in the theory of speech acts. In J. R. Searle, Consciousness and language (pp. 142-155). Cambridge, MA: Cambridge University Press.

Smith, L. (2009). Wittgenstein's rule-following paradox: How to resolve it with lessons for psychology. New Ideas in Psychology, 27(2), 228-242. doi:10.1016/j.newideapsych.2008.04.006

Strawson, P. F. (1964). Intention and convention in speech acts. Philosophical Review, 73, 439-460. doi: $10.2307 / 2183301$

Vygotsky, L. S. (1986). Thought and language. Cambridge, MA: MIT Press.

Wittgenstein, L. (1922). Tractatus Logico-Philosophicus. London: Routledge \& Kegan Paul.

Wittgenstein, L. (1968). Philosophical Investigations (G. E. M. Anscombe, Trans.) (3rd ed.). New York: Macmillan.

Sergey B. Kulikov - dean, universitywide department, Tomsk State Pedagogical University, D.Sc., associate professor.

Research area: cognitive psychology, history and philosophy of science, mapping capabilities and phenomenology of analytic philosophy on cognitive practices.

E-mail: kulikovsb@tspu.edu.ru 